Kong. Res. J. 3(2): 7-13, 2016

ISSN 2349-2694

Kongunadu Arts and Science College, Coimbatore.

\title{
A STUDY OF MUSA ACUMINATA (AAA GROUP) 'RED DACCA' FLOWER EXTRACT AS CORROSION INHIBITOR FOR MILD STEEL IN ACID MEDIA
}

\author{
Gunavathy N.* and S. Janet Mary Stella \\ Department of Chemistry, Nirmala College for Women, Coimbatore. \\ *E.mail: gunavathykrishnaprakash@yahoo.co.in
}

\begin{abstract}
The inhibitive effect of Musa acuminata Red Dacca flower extract in $1 \mathrm{~N} \mathrm{HCl} / \mathrm{H}_{2} \mathrm{SO}_{4}$ acid on mild steel was calculated using weight loss method and surface examination study by FTIR. The extract of the Red Dacca flower extract was subjected to preliminary phytochemical screening to identify the chemical constituents of the plant. The results revealed strong presence of tannins and steroids and moderate presence of, alkaloids, terpenoids, reducing sugar and coumarins. The corrosion inhibition efficiency studied showed that the inhibition efficiency increased with increase in the concentration of the extract. RD flower extract showed a maximum efficiency of $99.40 \%$ and $96.99 \%$ at $2.5 \% \mathrm{v} / \mathrm{v}$ in $1 \mathrm{~N} \mathrm{HCl}$ and $1 \mathrm{~N} \mathrm{H}_{2} \mathrm{SO}_{4}$ respectively.
\end{abstract}

Keywords: Musa acuminata Red Dacca, flower extract, acid medium, mild steel, FTIR.

\section{INTRODUCTION}

Mild steel finds a wide range of applications in industries, because of its availability, low cost, ease of fabrication and high tensile strength. But mild steel has a high tendency to corrode easily (Vinod Kumar et al., 2010). Use of inhibitors is one of the most practical methods for protection against corrosion. Present study deals with description of methods used in characterization of plant material and corrosion monitoring techniques. Corrosive inhibitive effect of flower extract of Musa acuminata Red Decca (Figure 1) in $1 \mathrm{~N} \mathrm{HCl} / \mathrm{H}_{2} \mathrm{SO}_{4}$, on mild steel was carried out using conventional weight loss method and surface examination analysis (FTIR).

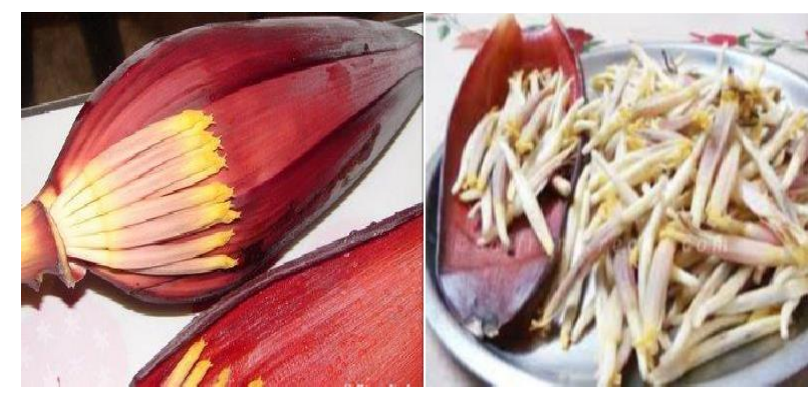

Fig. 1. Photograph of Musa acuminata Red Dacca flower

\section{MATERIALS AND METHODS}

\subsection{Phytoanalysis}

\subsubsection{Collection of plant materials}

Study was carried out on Musa acuminata Red Dacca flower extract, obtained from cultivated farm in Salem, Tamil Nadu, India. Dried sample was ground into powder (Figure 2) using an electronic blender, sieved and fine powder stored in air tight container.

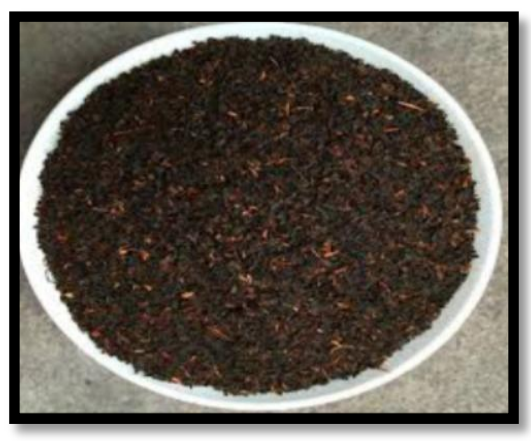

Fig. 2. RD Flower powder

\subsubsection{Phytochemical screening}

Extract of Musa acuminata Red Dacca flower extract was subjected to preliminary phytochemical screening to identify chemical constituents of plant, as described by various researchers Kotate (1999), Kotate 2010 and Harborne $(1984,1998)$.

\subsection{Corrosion studies}

\subsubsection{Preparation of the Inhibitor}

25 gm of dried powder of flower was boiled in $500 \mathrm{ml}$ of $1 \mathrm{~N} \mathrm{HCl} \mathrm{/} \mathrm{H} 2 \mathrm{SO} 4$ acid with reflux condenser (Figure 3) for three hours and kept overnight to extract its phytonutrients. Extract filtered and filtrate volume made up to $500 \mathrm{ml}$ using respective acids. Extract so prepared was taken as $5 \%$ stock solution and from this other concentrations were prepared. 


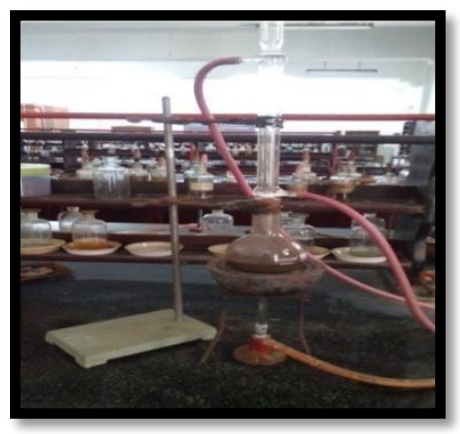

Fig. 3. Photograph of Experimental Set up for Obtaining Plant Extract

\subsubsection{Weight Loss Method}

\subsubsection{Preliminary treatment of mild steel}

Rectangular mild steel coupons of size $5 \times 1$ $\times 0.2 \mathrm{~cm}$ (Figure 4) cut from a large sheet of mild steel, with a small hole of about $1.0 \mathrm{~mm}$ diameter near the $1.5 \mathrm{~cm}$ side end for suspending were polished using silicon carbide emery papers of grade $200,400,600$, washed with distilled water, dried, degreased with acetone and dried and kept in desiccators to avoid adsorption of moisture.

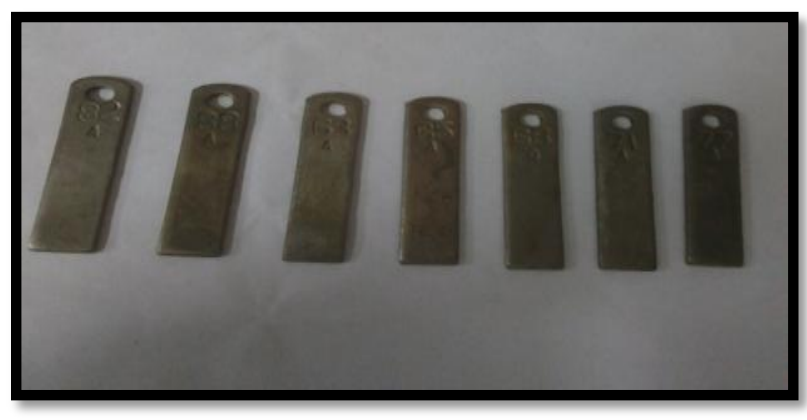

Fig. 4. Photograph of Mild Steel Coupons

\subsubsection{Immersion study}

Weight loss studies were conducted at room temperature. Mild steel specimens were weighed accurately in electronic balance. After initial weighing, the specimens were fully immersed using glass hooks in beakers containing $100 \mathrm{ml}$ of $1 \mathrm{~N} \mathrm{HCl} /$ $\mathrm{H}_{2} \mathrm{SO}_{4}$ wihout and with inhibitor of different concentrations $(0.1,0.5,1.0,1.5,2.0,2.5 \% \mathrm{v} / \mathrm{v})$ at various intervals of time $(1,3,5,7,12$ hours) (Figure 5). After the specified period of immersion, the specimens were removed, washed with distilled water, dried and reweighed.

\subsection{Surface examination studies}

Surface analysis studies FTIR of mild steel specimens were done in order to study changes that occur during corrosion of mild steel in presence and absence of inhibitor in acid media (Raja and Sethuraman, 2008, 2009).

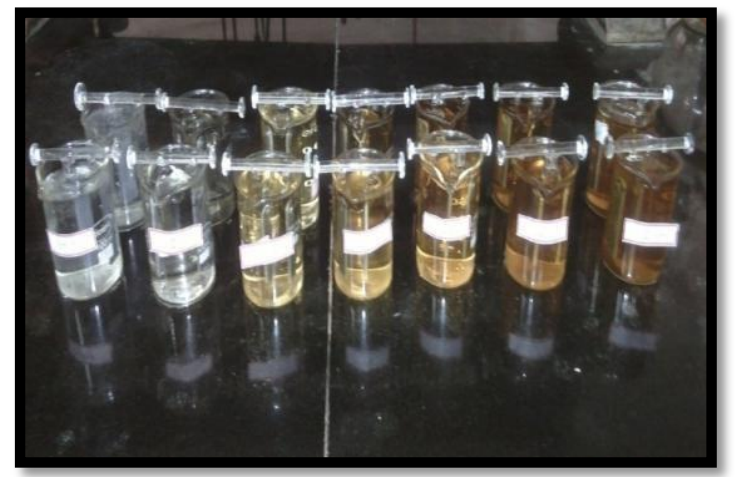

Fig. 5. Photograph of specimens fully immersed in acid medium without and with inhibitor

\subsubsection{Preparation of the specimen for surface analysis.}

Mild steel specimens $(5 \times 1 \times 0.2 \mathrm{~cm})$ were abraded with emery paper of grade 400 and 600 to a mirror finish, washed with distilled water and then rinsed with acetone and dried by hot air drier (Hegazy et al., 2011).

\subsubsection{Surface morphology studies by Fourier Transform Infrared spectroscopy}

Mild steel specimens were immersed in $1 \mathrm{~N}$ $\mathrm{HCl} / \mathrm{H}_{2} \mathrm{SO}_{4}$ solution in absence and presence of $2 \%$ $\mathrm{v} / \mathrm{v}$ concentration of RD flower extracts for a period of three hours at room temperatue, removed,washed carefully with distilled water without disturbing the suface and dried. FTIR spectra of the samples were taken at Bharathiar University, Coimbatore, India (Model : Shimazdu).

\section{RESULTS AND DISCUSSION}

\subsection{Qualitative phytochemical analysis}

Phytochemicals present in aqueous flower extract of Red Dacca are summarized in Table 1. Results indicated that reducing sugar, saponins, coumarins and steroids were moderately present in the RD (F) extract. RD (F) extract showed the active presence of alkaloids and terpenoid. Exceptional factor was tannin content seem to be high in RDF extract of Red Dacca flower. It is evident from the tabulation that the other phyto chemicals like carbohydrates, flavonids, phlobotannins, cycloglycosides, total phenols, quinones and anthraquinones were absent in extract of Musa acuminata Red Dacca flower.

These results suggest the presence of primary bioactive metabolites of commercial importance which acts as the precursors for the synthesis of secondary metabolites. These in turn help in development of new bio products as corrosion inhibitor for future. 
Table 1. Phytochemical constituents present in the extract of Musa acuminata Red Dacca flower

\begin{tabular}{lc}
\hline \multicolumn{1}{c}{ Phytocompound } & RD (F) extract \\
\hline Carbohydrates & + \\
Reducing sugars & ++ \\
Alkaloids & + \\
Saponins & ++ \\
Tannins & +++ \\
Flavonoids & - \\
Terpernoids & + \\
Phlobotannins & - \\
Coumarins & ++ \\
Cycloglycosides & - \\
Total phenols & - \\
Quinones & - \\
Anthraquinones & - \\
Steroids & ++ \\
\hline $\begin{array}{l}\text { Key: '+++' active compound copiously } \\
\text { compresent, '++' active } \\
\text { active compound absent. }\end{array}$ &
\end{tabular}

\subsection{Weight loss studies}

Mild steel was found to corrode in $1 \mathrm{~N} \mathrm{HCl} /$ $\mathrm{H}_{2} \mathrm{SO}_{4}$ acid solution. This was evidenced by the decrease in the original weight of the metal coupons. With addition of plant extract to the acids, it was found that weight loss decreases with increase in concentration from 0.1 to $2.5 \% \mathrm{v} / \mathrm{v}$ due to adsorption of plant nutrient and protects from dissolution of metal (Loto, 2011).

3.2.1. Effect of Concentration of RD flower Extract on Concentration Rate and Inhibition Efficiency

Variation of inhibition efficiency and corrosion rate with change in concentration of the inhibitor is presented in Table 2 and Table 3. It is obvious from the data that there was decrease in the corrosion rate with increase in the inhibitor concentration for all immersion periods. The decrease in corrosion rate and increase in inhibitor efficiency was usually attributed to the adsorption of flower extract constituents on the surface of mild steel which makes a barrier for mass and charge transfers and protects further attack by the acid (Saratha and Vasudha, 2009).

Table 2. CR of mild steel and IE of RD (F) extract in $1 \mathrm{~N} \mathrm{HCl}$ acid in various concentration and immersion period.

\begin{tabular}{|c|c|c|c|c|c|c|c|c|c|c|}
\hline \multirow{2}{*}{$\begin{array}{c}\begin{array}{c}\text { Conc. } \\
\text { of } \\
\text { Extract }\end{array} \\
(\%)\end{array}$} & \multicolumn{2}{|c|}{$1 \mathrm{~h}$} & \multicolumn{2}{|c|}{$3 h$} & \multicolumn{2}{|c|}{$5 h$} & \multicolumn{2}{|c|}{$7 \mathrm{~h}$} & \multicolumn{2}{|c|}{$24 \mathrm{~h}$} \\
\hline & $\begin{array}{c}\text { CR } \\
\mathrm{mm} / \mathrm{y}\end{array}$ & $\begin{array}{c}\text { IE } \\
(\%)\end{array}$ & $\begin{array}{c}\mathrm{CR} \\
\mathrm{mm} / \mathrm{y}\end{array}$ & $\begin{array}{l}\text { IE } \\
(\%)\end{array}$ & $\begin{array}{c}\mathrm{CR} \\
\mathrm{mm} / \mathrm{y}\end{array}$ & $\begin{array}{c}\text { IE } \\
(\%)\end{array}$ & $\begin{array}{c}\mathrm{CR} \\
\mathrm{mm} / \mathrm{y}\end{array}$ & $\begin{array}{c}\text { IE } \\
(\%)\end{array}$ & $\begin{array}{c}\text { CR } \\
\mathrm{mm} / \mathrm{y}\end{array}$ & $\begin{array}{c}\text { IE } \\
(\%)\end{array}$ \\
\hline Blank & 32.32 & - & 35.66 & - & 37.22 & - & 44.73 & - & 83.72 & - \\
\hline 0.1 & 6.68 & 79.31 & 4.82 & 85.08 & 15.15 & 59.29 & 31.84 & 29.20 & 2.55 & 25.65 \\
\hline 0.5 & 5.57 & 84.56 & 2.22 & 93.13 & 4.68 & 87.42 & 3.82 & 91.37 & 2.46 & 28.27 \\
\hline 1.0 & 3.34 & 89.6 & 1.85 & 94.27 & 3.34 & 91.02 & 1.75 & 94.74 & 2.32 & 32.06 \\
\hline 1.5 & 3.34 & 90.62 & 1.48 & 95.40 & 2.00 & 94.62 & 1.91 & 95.72 & 2.04 & 40.52 \\
\hline 2.0 & 2.22 & 92.1 & 1.11 & 96.56 & 1.33 & 96.42 & 1.59 & 96.44 & 1.57 & 54.22 \\
\hline 2.5 & 1.20 & 93.1 & 0.74 & 97.70 & 0.22 & 99.40 & 1.11 & 97.51 & 1.48 & 56.85 \\
\hline
\end{tabular}

Table 3. CR of mild steel and IE of RD (F) extract in $1 \mathrm{~N} \mathrm{H}_{2} \mathrm{SO}_{4}$ acid in various concentration and immersion period.

\begin{tabular}{|c|c|c|c|c|c|c|c|c|c|c|}
\hline \multirow{2}{*}{$\begin{array}{c}\text { Conc. } \\
\text { of } \\
\text { Extract } \\
(\%)\end{array}$} & \multicolumn{2}{|c|}{$1 \mathrm{~h}$} & \multicolumn{2}{|c|}{$3 h$} & \multicolumn{2}{|c|}{$5 h$} & \multicolumn{2}{|c|}{$7 \mathrm{~h}$} & \multicolumn{2}{|c|}{$24 \mathrm{~h}$} \\
\hline & $\begin{array}{c}\mathrm{CR} \\
\mathrm{mm} / \mathrm{y}\end{array}$ & $\begin{array}{c}\text { IE } \\
(\%)\end{array}$ & $\begin{array}{c}\mathrm{CR} \\
\mathrm{mm} / \mathrm{y}\end{array}$ & $\begin{array}{c}\text { IE } \\
(\%)\end{array}$ & $\begin{array}{c}\mathrm{CR} \\
\mathrm{mm} / \mathrm{y}\end{array}$ & $\begin{array}{c}\text { IE } \\
(\%)\end{array}$ & $\begin{array}{c}\mathrm{CR} \\
\mathrm{mm} / \mathrm{y}\end{array}$ & $\begin{array}{l}\text { IE } \\
(\%)\end{array}$ & $\begin{array}{c}\mathrm{CR} \\
\mathrm{mm} / \mathrm{y}\end{array}$ & $\begin{array}{c}\text { IE } \\
(\%)\end{array}$ \\
\hline $\begin{array}{l}\text { Blank } \\
\end{array}$ & 42.35 & - & 75.22 & - & 79.57 & - & 79.28 & - & 83.72 & - \\
\hline 0.1 & 10.03 & 71.87 & 22.38 & 70.74 & 15.15 & 80.96 & 10.50 & 86.75 & 27.76 & 66.84 \\
\hline 0.5 & 7.80 & 78.12 & 9.93 & 88.03 & 10.47 & 86.84 & 7.80 & 90.16 & 23.77 & 71.60 \\
\hline 1.0 & 5.57 & 86.84 & 8.08 & 89.36 & 6.90 & 91.32 & 5.87 & 92.57 & 19.87 & 76.25 \\
\hline 1.5 & 4.45 & 89.49 & 7.05 & 90.64 & 5.34 & 93.28 & 3.98 & 94.97 & 16.85 & 79.87 \\
\hline 2.0 & 3.34 & 92.11 & 5.01 & 93.35 & 4.01 & 94.96 & 3.02 & 96.19 & 14.48 & 82.69 \\
\hline 2.5 & 2.22 & 94.22 & 4.17 & 94.68 & 3.78 & 95.24 & 2.38 & 96.99 & 13.83 & 83.47 \\
\hline
\end{tabular}


3.2.2. Effect of Immersion Time on Corrosion Rate and Inhibition Efficiency

Variation of inhibitor efficiency with inhibitor concentration and immersion time is given in figure $6 \mathrm{a}$ and $6 \mathrm{~b}$. The inhibition efficiency increased with increase in concentration of the inhibitor from 0.1 to $2.5 \%$ at room temperature. The maximum inhibition efficiency was $99.40 \%$ in case of $\mathrm{RD}(\mathrm{F})$ extract in $1 \mathrm{~N} \mathrm{HCl}$ for the immersion period of $5 \mathrm{~h}$ and $96.99 \%$ for $\mathrm{RD}(\mathrm{F})$ extract in $1 \mathrm{~N} \mathrm{H}_{2} \mathrm{SO}_{4}$ for the immersion period of $7 \mathrm{~h}$ at a concentration of 2.5 $\% \mathrm{v} / \mathrm{v}$. The decrease in inhibition efficiency thereafter with increasing time may be due to the shift in adsorption and desorption equilibrium which takes place simultaneously on prolonged exposure to the corrosive media (Putilova, 1960). These results suggest that the adsorption model arrangement and orientation of the constituents present in the Red Decca extract on the surface of mild steel may change with time (Rekha Nair, 2010). At low concentration, the aromatic rings of the phyto constituents may be oriented perpendicularly with respect to the metal surface. But at higher concentrations of inhibitor, the molecules may be reoriented to the parallel mode on the surface of mild steel. Therefore for higher concentration of inhibitor, more number of inhibitor molecules gets adsorbed on the surface of mild steel (Patel, 2009).

The adsorption of the phyto constituents on the metal surface makes a barrier for mass and charge transfers and thus protects the metal surface fraction occupied by the adsorbed molecules (Shymala and Arulanantham, 2009).
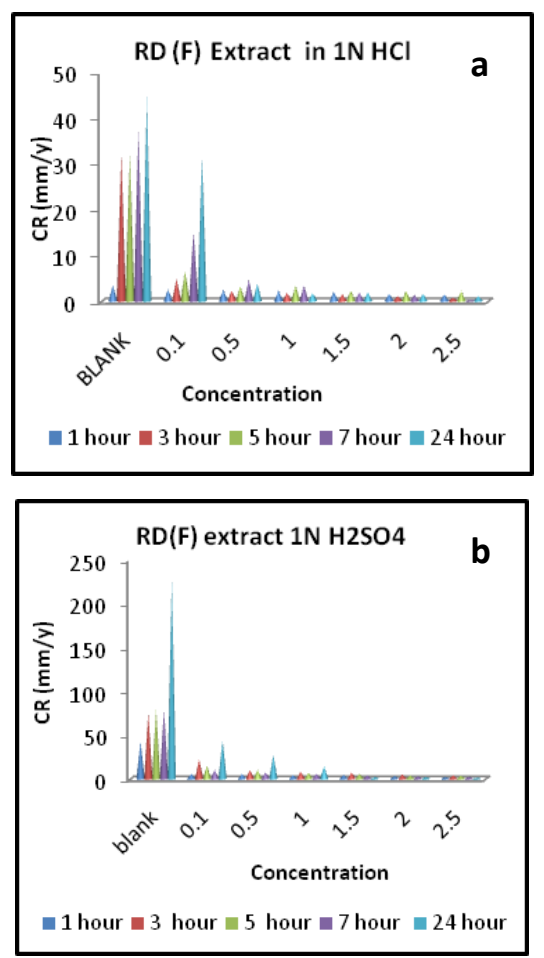

Fig. 6. Effect of concentration on CR of mild steel in (a) $1 \mathrm{~N} \mathrm{HCl} \mathrm{(b)} 1 \mathrm{~N} \mathrm{H}_{2} \mathrm{SO}_{4}$ without and with $\mathrm{RD}$ (F) Extract.

3.4. Fourier transform infrared spectroscopy (FTIR) studies

Results of FTIR of Mild steel exposed to $1 \mathrm{~N}$ $\mathrm{HCl}$ and $1 \mathrm{~N}_{2} \mathrm{SO}_{4}$ in the presence of Musa acuminata Red Dacca Flower extract and possible functional group (Harajothi Mazumdar 2010), are represented Table 4 Table 5.

Table 4. FTIR peak values and possible functional group of adsorption layer formed on mild steel surface exposed to $1 \mathrm{~N} \mathrm{HCl}$ without and with RD (F) inhibitor.

\begin{tabular}{llc}
\hline Mild Steel in 1N HCl & \multicolumn{1}{c}{ Possible groups } & Mild Steel in 1N HCl with RD(F) extract \\
\hline & Methylene $\mathrm{CH}$ asy/sym (S) & 2850.27 \\
& Methoxy O-CH & \\
& Methyl ether C-H(S) & \\
& Methylamino \\
& $\mathrm{N}-\mathrm{CH}_{3}, \mathrm{CH}(\mathrm{S})$ & 2785.67
\end{tabular}

2678.64

2669.00

2608.25

2508.94

2440.47

$\mathrm{N}-\mathrm{H}$ ammonium ions

2552.33

Multiple broad peaks

2505.08

2400.94

2392.26

2366.26

2347.91

2334.41 
Nitrile

Transition metal carbonyl

Fluoro alkanes

Skeletal C-C vibration

1056.80

1015.34 Aromatic $\mathrm{CH}$ in plane bend Aromatic fluoro compounds C-F(S)

$554.43 \quad$ Aliphatic iodo compounds C-I (S)

Table 5. FTIR peak values and possible functional group of adsorption layer formed on mild steel surface exposed to $1 \mathrm{~N}_{2} \mathrm{SO}_{4}$ without inhibitor.

\begin{tabular}{|c|c|c|}
\hline \multirow[t]{16}{*}{ Mild steel in $1 \mathrm{~N} \mathrm{H}_{2} \mathrm{SO}_{4}$} & Possible groups & Mild steel in $1 \mathrm{~N} \mathrm{H}_{2} \mathrm{SO}_{4}$ with $\mathrm{RD}(\mathrm{F})$ extract \\
\hline & Primary alcohol / Phenol & 3639.02 \\
\hline & $\mathrm{OH}(\mathrm{S})$ & 3532.95 \\
\hline & Heterocyclic amines N-H (S) & 3440.39 \\
\hline & Dimeric OH (S) & \\
\hline & OH carboxylic acid & \\
\hline & NH primary amine & \\
\hline & Normal polymeric $\mathrm{OH}$ & 3297.68 \\
\hline & Alkynes & 3232.11 \\
\hline & $\begin{array}{l}\mathrm{N}-\mathrm{H} \text {, ammonium ions } \\
\text { Multiple broad peaks }\end{array}$ & 3156.90 \\
\hline & Methylene C-H (S) & 2892.70 \\
\hline & Alkyl C=H & \\
\hline & Aldehyde CHO & \\
\hline & Methoxy C-H (S) & 2811.70 \\
\hline & Alkyl C=H & \\
\hline & Aldehyde $\mathrm{CHO}$ & \\
\hline 2790.49 & & \\
\hline 2655.50 & & \\
\hline 2592.82 & & \\
\hline 2519.54 & & \\
\hline & & 2491.58 \\
\hline 2458.80 & $\mathrm{~N}-\mathrm{H}$ Ammonium ions & \\
\hline & Multiple broad peaks & \\
\hline & & 2413.48 \\
\hline 2393.23 & & \\
\hline & & 2354.66 \\
\hline & & 2335.37 \\
\hline 2333.45 & & \\
\hline 2268.20 & Nitrile & \\
\hline & Cyanate OCN, C-OCN & \\
\hline & Isocyanate $-\mathrm{N}=\mathrm{C}=\mathrm{O}$ asy $(\mathrm{S})$ & \\
\hline 2239.91 & Isothiocyanate (-NCS) & \\
\hline 2116.49 & $\mathrm{C} \equiv \mathrm{C}$ terminal alkynes & \\
\hline & CH alkynes & 707.75 \\
\hline & $\mathrm{C}-\mathrm{H}(\mathrm{b})$ of aromatic & \\
\hline & Cis C-H out of plane bend & \\
\hline & Aliphatic chloro compounds & \\
\hline & $\mathrm{C}-\mathrm{Cl}(\mathrm{S})$ & \\
\hline
\end{tabular}




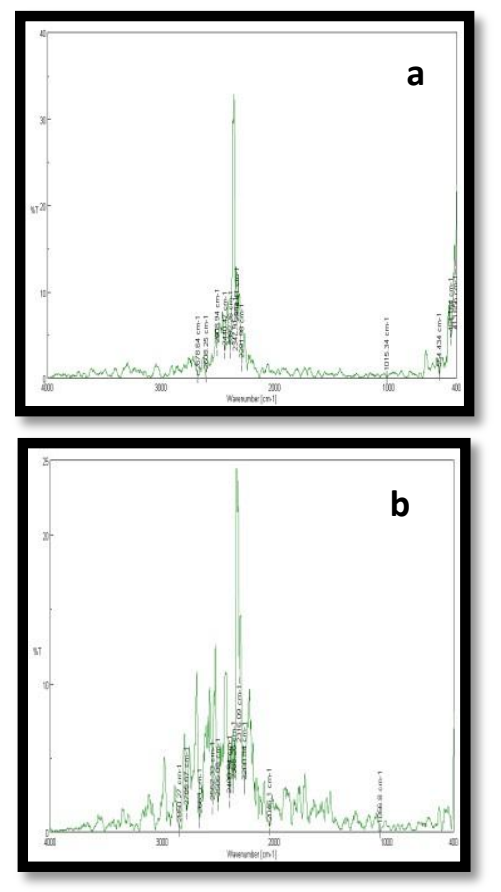

Fig. 7. FTIR spectra of adsorption layer formed on the mild steel surface immersion in $1 \mathrm{~N} \mathrm{HCl}$ acid (a) without (b) with RD (F) extract.

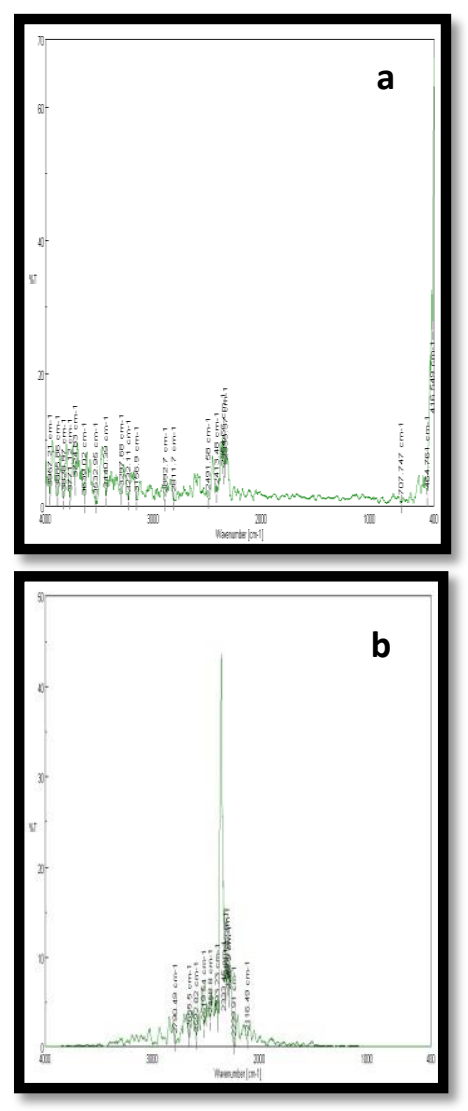

Fig. 8. FTIR spectra of adsorption layer formed on the mild steel surface immersion in $1 \mathrm{~N} \mathrm{H}_{2} \mathrm{SO}_{4}$ acid (a) without (b) with RD (F) extract.

\subsubsection{Analysis of FTIR spectra}

FTIR spectra of mild steel treated with $1 \mathrm{~N}$ $\mathrm{HCl} / \mathrm{H}_{2} \mathrm{SO}_{4}$ without and with $\mathrm{RD}$ flower extract displayed in Figure $7 \mathrm{a}$ and $7 \mathrm{~b}$ and $8 \mathrm{a}$ and $8 \mathrm{~b}$, showed either a decrease in the transmittance or disappearance of some of the above said bands, giving a strong evidence for the interaction between the metal and the functional groups such as $\mathrm{OH}, \mathrm{NH}_{2}$ and $\mathrm{C}=\mathrm{O}$ leading to the formation of film of large surface coverage which serve as a barrier between the corrosive acid medium and the metal thereby inhibiting corrosion and also revealing the fact that Musa acuminata Red Dacca flower nutrients can absorb on the metal surface on the basis of donoracceptor interactions between lone-pair electrons of $\mathrm{N}$ and the vacant d-orbital of Fe substrate (Deng $2011 \mathrm{a}, \mathrm{b})$.

\section{CONCLUSION}

Qualitative analysis of Musa acuminata Red Decca flower extract showed presence of alkaloids, saponins, tannins, flavonoids, terpenoids, coumarins, phenols and steroids. Corrosion of mild steel in $1 \mathrm{~N}$ $\mathrm{HCl} / \mathrm{H}_{2} \mathrm{SO}_{4}$ acid medium was significantly reduced upon the additions of RD flower extract. Inhibition efficiency increased with increasing concentration of inhibitor. Maximum inhibitor efficiency was observed at an optimum concentration of $2.5 \% \mathrm{v} / \mathrm{v}$. The flower extract of RD showed maximum efficiency of $99.40 \%$ in $1 \mathrm{~N} \mathrm{HCl}$ at 5 hours of immersion. The flower extract of $\mathrm{RD}$ showed maximum efficiency of $96.99 \%$ in $1 \mathrm{~N} \mathrm{H}_{2} \mathrm{SO}_{4}$ at 7 hours of immersion. RD (F) extract showed better inhibitive effect in $1 \mathrm{~N} \mathrm{HCl}$ when compared to $\mathrm{H}_{2} \mathrm{SO}_{4}$. Whereas RD (F) had better inhibitive effect spread throughout the various concentrations from 0.1 to $2.5 \% \mathrm{v} / \mathrm{v}$ in $\mathrm{HCl}$ medium. All the results of the present study indicate that the extracts Red Decca flower in $1 \mathrm{~N} \mathrm{HCl} / \mathrm{H}_{2} \mathrm{SO}_{4}$ acid can be used as corrosion inhibitors for mild steel. Further, as these extracts are environmental friendly, they can be considered as green corrosion inhibitors.

\section{REFERENCES}

Deng, S., X. Li and H. Fu, (2011a). Acid violet 6B as a novel corrosion inhibitor for cold rolled steel in hydrochloric acid solution. Corros. Sci. 53: 760768.

Deng, S., X. Li and H. Fu, (2011b). Two pyrazine derivatives as inhibitors of the cold rolled steel corrosion in hydrochloric acid solution. Corros. Sci. 53: 822-828.

Harajyoti Mazumdar and G.U. Ahmed, (2011). Phytotoxicity effect of silver nanoparticles on 
Oryza sativa. Int. J. ChemTech Res., 3(3): 14941500.

Harborne, J.B., (1984). Phytochemical Methods: A guide to modern techniques of plant analysis, Chapman and Hall, London, $2^{\text {rd }}$ Ed.

Harborne, J.B., (1998). Phytochemical Methods: A guide to modern techniques of plant analysis, Chapman and Hall, London, $3^{\text {rd }}$ Ed., pp.302.

Hegazy, M.A., H.M. Ahmed and A.S. El-Tabei, (2011). Investigation of the inhibitive effect of psubstituted $\quad 4-(\mathrm{N}, \quad \mathrm{N}, \quad \mathrm{N}$-dimethyldodecyl ammonium bromide) benzylidene-benzene-2yl-amine on corrosion of carbon steel pipelines in acidic medium. Corros. Sci., 53: 671-678.

Kokate, A., (1999). Phytochemical methods. Phytotherapy Res. 78: 126-129

Kokate, C.K, A.P. Purohit and S.B. Gokhale, (2010). Pharmacognosy, Nirali prakashan, Pune, 6.156.36, 2010.

Loto, C.A. and A.P.I. Popoola, (2012). Effect of Cola Acuminata and Camellia Sinensis mixed extracts on the corrosion inhibition of mild steel in $0.5 \mathrm{M}$ sulphuric acid. Int. J. Electrochem. Sci. 7: 29832996.

Loto, C.A., R.T. Loto and A.P.I. Popoola, (2011). Corrosion and plants extracts inhibition of mild steel in HCl. Int. J. Phys. Sci. 6(15): 3689-3696.
Patel, N.S., S. Jauhari and G.N. Mehta, (2009). Mild steel corrosion inhibition by Bauhinia Purpurea leaves extract in $1 \mathrm{~N}$ sulphuric acid. Arb. J. Sci. Eng. 34(2C): 61-69.

Putilova, I.N., S.A. Balezin and V.P. Barannik, (1960). Metallic corrosion inhibitors, Pergamon Press, London, pp.204.

Raja, P.B. and M.G. Sethuraman, (2008). Natural products as corrosion inhibitor for metals in corrosive media-A review. Mat. Lett. 62(1): 113-116.

Raja, P.B. and M.G. Sethuraman, (2009). Solanum tuberosum as an inhibitor of mild steel corrosion in acid media. Iran. J. Chem. Chem. Eng. 28(1): 77-84.

Rekha Nair, Shashi Sharma, I.K. Sharma, P.S. Verma and Alka Sharma, (2010). Inhibitor efficacy of Piper Nigrum Linn. extract on corrosion of AA1100 in HCl. Rasayan J. Chem. 3(4): 783-795.

Saratha, R. and V.G. Vasudha, (2009). Inhibition of mild steel corrosion in $1 \mathrm{~N}_{2} \mathrm{SO}_{4}$ medium by acid extract of Nyctanthes arbortristis leaves. $E$. J. Chem. 6(4): 1003-1008.

Vinod Kumar, K.P., M.S. Narayanan Pillai and G. Rexin Thusnavis, (2010). Pericarp of the fruit of Garcinia Mangostana as corrosion inhibitor for mild steel in hydrochloric acid medium. Portugaliae Electrochim. Acta. 28(6): 373-383. 